\title{
ANALISIS TINGKAT KETEPATAN WAKTU KRL COMMUTER LINE TANAH ABANG - RANGKASBITUNG (STUDI KASUS: STASIUN TANAH ABANG)
}

\author{
David Siwi $^{1}$, Dewi Linggasari ${ }^{2}$, dan Hokbyan R.S. Angkat ${ }^{3}$ \\ ${ }^{1}$ Program Studi Sarjana Teknik Sipil, Universitas Tarumanagara, Jl. Letjen S. Parman No.1 Jakarta \\ david.325160097@stu.untar.ac.id \\ ${ }^{2}$ Program Studi Sarjana Teknik Sipil, Universitas Tarumanagara, Jl. Letjen S. Parman No.1 Jakarta \\ dewil@ft.untar.ac.id \\ ${ }^{3}$ Program Studi Sarjana Teknik Sipil, Universitas Tarumanagara, Jl. Letjen S. Parman No.1 Jakarta \\ hokbyan@gmail.com
}

Masuk: 06-07-2020, revisi: 01-09-2020, diterima untuk diterbitkan: 22-10-2020

\begin{abstract}
KRL Commuter Line as one of the transportation options is preferred in Jabodetabek because of its ability to meet the needs of large quantity of passengers. The title of this thesis is the Punctuality Analysis of the Commuter Line KRL Tanah Abang - Rangkasbitung Line (Case Study: Tanah Abang Station). The purpose of this study is to identify the departure's punctuality towards the Green Line KRL schedule and classifying the departure delay rate and determining a solution to reduce the delay rate on the Green Line KRL. The method used is an online questionnaire and a field survey. Then it is analyzed by Gap Analysis in order to obtain information about the individual characteristics of Green Line KRL users in Tanah Abang Station. Tanah Abang Station respondents are $71 \%$ men and $29 \%$ women, consist $72 \%$. users who aged $21 \%-30$ years. $79.3 \%$ originated from DKI Jakarta Province with a S1 degree of $61 \%$, the data shows that the passenger is 74\% students. With expense ranged Rp 1,000,000 - Rp 2,000,000 per month. Most passengers use train to go to school/home. 76.8\% respondents use KRL upon needs.
\end{abstract}

Keywords: Green Line KRL; Gap Analysis; Individual Characteristic; Departure Characteristic

\begin{abstract}
ABSTRAK
Salah satu moda transportasi yang diminati masyarakat Jabodetabek adalah KRL Commuter Line karena kemampuannya menampung penumpang dalam jumlah besar menjadikan KRL Commuter Line sebagai salah satu moda transportasi yang sangat diminati masyarakat luas. Judul penelitian ini adalah Analisis Tingkat Keterlambatan KRL Commuter Line Lintas Tanah Abang- Rangkasbitung (Studi Kasus: Stasiun Tanah Abang). Tujuan penelitian ini adalah untuk mengindentifikasi ketepatan waktu keberangkatan KRL Green Line dengan penjadwalannya di Stasiun Tanah Abang serta mengklasifikasikan tingkat keterlambatan keberangkatan KRL Green Line dan menentukan solusi untuk mengurangi tingkat keterlambatan keberangkatan KRL Green Line. Metode Penelitian yang digunakan adalah kuesioner online dan survei lapangan. Lalu dianalisis dengan Gap Analysis agar didapatkan informasi mengenai karateristik individu dan karateristik perjalanan pengguna KRL Green Line di Stasiun Tanah Abang. Pengguna Stasiun Tanah Abang mayoritas laki - laki sebesar 71\% dan Wanita 29\%, berdasarkan data responden, didominasi konsumen berumur 21 - 30 tahun sebesar $72 \%$. Didapat sebesar 79,3\% berdomisilli dari Provinsi DKI Jakarta berpendidikan S1 sebesar $61 \%$ sehingga data menunjukan profesi konsumen adalah sebesar $74 \%$ pelajar/mahasiswa. Dengan pengeluaran rata-rata per bulan sebesar Rp 1.000.000 - Rp 2.000.000. Rata-rata menunjukan bahwa konsumen Stasiun Tanah Abang menggunakan KA untuk sekolah/pulang. Responden sepakat bahwa frekuensi penggunaan KA bersifat sesuai kebutuhan (76,8\%).
\end{abstract}

Kata kunci: KRL Green Line; Gap Analysis; Karakteristik individu; Karakteristik Perjalanan

\section{PENDAHULUAN}

Kereta api merupakan salah satu moda transportasi yang berada di Jakarta. Keberadaan kereta api sendiri merupakan pilihan utama bagi sebagian warga Jakarta pada umumnya. Salah satu keunggulan yang dimiliki kereta api dibandingkan moda transportasi lain adalah ketepatan waktu. Sehingga konsumen sangat mengharapkan ketepatan waktu di kereta api sesuai dengan jadwalnya. 
Abang)

Tidak bisa dipungkiri bahwa transportasi darat di Jakarta sangat tidak efisien karena alasan kemacetan yang luar biasa parah di Jakarta. Kereta api sendiri bisa memberikan solusi untuk kemacetan, termasuk gerbong nya yang panjang dapat mengangkut massal, dan seandainya melintas, diutamakan dibandingkan moda transportasi darat lainnya, sehingga kereta api tidak akan mengalami kemacetan.

Stasiun Tanah Abang sebagai lokasi studi kasus dipilih karena Tanah Abang sendiri merupakan pusat perbelanjaan yang sangat besar di Jakarta, sehingga Tanah Abang sangat membantu perkembangan ekonomi di Jakarta, karenanya diperlukan KRL agar tidak terlambat sehingga tidak menghambat pertumbuhan ekonomi di Jakarta, namun pada kenyataannya keterlambatan KRL masih sering terjadi.

Untuk memajukan sektor transportasi di Indonesia, ketepatan waktu KRL harus di optimalkan sehingga keterlambatan jarang terjadi. Ketepatan waktu KRL Stasiun Tanah Abang dibandingkan dengan persepsi atau toleransi keterlambatan menurut pengguna KRL di jalur Green Line (secara keseluruhan), dan toleransi keterlambatan pengguna KRL di Stasiun Tanah Abang melalui Google Form, dan sebagai tambahan dibandingkan dengan toleransi keterlambatan menurut Peraturan Menteri nomor 63 tahun 2019 tentang Standar Pelayanan Minimum.

Rumusan masalah yang akan dibahas adalah:

1. Bagaimana cara mengidentifikasi keterlambatan keberangkatan KRL Green Line?

2. Bagaimana mengklasifikasi tingkat keterlambatan keberangkatan KRL Green Line?

3. Apa solusi yang bisa diterapkan untuk mengatasi masalah keterlambatan keberangkatan KRL Green Line ?

Adapun beberapa tujuan dari penelitian ini adalah:

1. Mengidentifikasi keterlambatan keberangkatan KRL Green Line di Stasiun Tanah Abang.

2. Mengklasifikasi keterlambatan keberangkatan KRL Green Line di Stasiun Tanah Abang.

3. Mencari solusi yang bisa diterapkan untuk mengatasi masalah keterlambatan keberangkatan KRL Green Line di Stasiun Tanah Abang.

\section{Kereta rel listrik}

Dahulu kala, kereta hanya digunakan untuk tujuan pertambangan, lalu setelah perkembangan zaman, kereta mulai digunakan untuk menarik gerbong penumpang dengan lokomotif tenaga uapnya. Untuk menunjang efektivitas dan kemajuan, beberapa perusahaan lokomotif mengembangkan ide baru yaitu dengan menciptakan kereta listrik. Kereta Listrik menggunakan listrik sebagai daya untuk menggerakan mesin kereta. (Kompas).

KRL seperti kereta api pada umumnya merupakan suatu moda transportasi massal yang menggunakan listrik sebagai penggerak rodanya. Energi listrik yang digunakan oleh KRL berasal dari PLN yang didistribusikan dari gardu-gardu yang dimiliki PLN langsung ke KRL melalui sistem Pusat Listrik Aliran Atas (PLAA). PLAA yang dipakai menggunakan jenis arus searah, sehingga dalam gardu tersebut harus dipasang konverter yang mengubah dari arus bolak balik (ABB) menjadi arus searah (AS). (Sabri and Kurniawan)

\section{Hubungan ketepatan waktu dengan konsep manajemen}

PT KCI sangat mementingkan kepuasan konsumen, dalam hal ini kepuasan konsumen difokuskan kepada ketepatan waktu. Ketepatan waktu sendiri merupakan alasan utama konsumen kereta api memilih menggunakan kereta api dibandingkan menggunakan sarana transportasi lainnya seperti angkutan kota (Angkot), transjakarta, dan ojek online. Kereta api sendiri memiliki lebih sedikit faktor keterlambatan dibandingkan dengan transportasi lainnya, alasan utamanya adalah kereta api memiliki jalur yang tidak bisa diakses oleh sarana transportasi lain, sedangkan bus Transjakarta yang memiliki jalur Busway sendiri masih dapat dilalui oleh kendaraan lain seperti mobil pribadi, motor, dll.

\section{Standar Pelayanan Minimum, ketepatan waktu, dan GAPEKA}

Standar Pelayanan Minimum adalah ukuran minimum pelayanan yang harus dipenuhi oleh pihak penyelenggara dalam memberikan layanan kepada konsumen. (Alim and Syahirul). Untuk memenuhi izin menjalani kegiatan operasional kereta api, penyelenggara harus menyiapkan kereta api yang memenuhi Standar Pelayanan Minimum (SPM). SPM kereta api diatur dalam “ Peraturan Menteri Perhubungan Republik Indonesia Nomor PM 63 Tahun 2019 Tentang Standar Pelayanan Minimum Angkutan Orang Dengan Kereta Api”. Pada Penelitian ini, penulis berfokus kepada SPM bagian ketepatan waktu.

Yang dimaksud dengan ketepatan waktu adalah jarak antara kedatangan dan keberangkatan sesuai dengan waktu yang disepakati oleh pihak berwenang (Nyström). Pada penelitian ini, ketepatan waktu mengacu penuh kepada penjadwalan KRL di stasiun. 
Ketepatan waktu khususnya pada kereta api adalah kesesuaian waktu dari keberangkatan (Departure) sampai kedatangan (Arrival) kereta terhadap jadwal resmi dari PT KAI yaitu Grafik Perjalanan Kereta Api (GAPEKA). GAPEKA sendiri menjadi pedoman atas pengaturan perjalanan kereta api yang dibuat dalam bentuk gambaran garis yang menunjukkan stasiun, jarak, kecepatan, waktu, dan posisi perjalanan kereta api dari keberangkatan, persilangan, bersusulan sampai berhenti yang dibuat untuk pengendalian perjalanan kereta api. (Apriyadi). Dalam GAPEKA berisikan nomor kereta api, serta nama kereta api, lintas, dan jarak antar stasiun, waktu keberangkatan dan kedatangan, kecepatan yang diijinkan untuk kereta api, waktu perjalanan dan tempat penyusulan, dan tempat bersilang kereta api. Dalam Peraturan Pemerintah No. 72 tahun 2009 tentang Lalu Lintas dan Angkutan Kereta Api menjelaskan bahwa perjalanan kereta api harus sesuai dengan jadwal yang telah ditentukan dalam GAPEKA. (Muctar)

Dalam PP No. 72 tahun 2009 menjelaskan jika terjadi jadwal keterlambatan kereta api mengalami keterlambatan diatas batas toleransi yang seharusnya, pihak berwenang yang bertugas sebagai penyelenggara prasarana kereta api perlu mengambil langkah-langkah untuk mengurangi keterlambatan perjalanan kereta api. Selanjutnya menurut Kepmenhub 22 tahun 2003 tentang Pengoperasian Kereta Api, untuk mengatasi keterlambatan jadwal perjalanan kereta api yang melebihi batas toleransi waktu operasi yang diizinkan, diusahakan :

1. Turun-naik penumpang dan muat-bongkar barang dipercepat.

2. Waktu berhenti di stasiun/perhentian dipercepat.

3. Masinis menjalankan kereta apinya sesuai batas kecepatan maksimum operasi yang diizinkan.

4. Jika keadaan terapaksa dapat dilakukan pemindahan persilangan atau penyusulan dengan kereta api lain agar kereta api lainnya tidak mengalami keterlambatan. (Muctar)

\section{Penyebab keterlambatan waktu perjalanan kereta api}

Keterlambatan dalam pengoperasian kereta dapat dilihat ketika kereta yang tiba tidak sesuai dengan jadwal yang sudah ditentukan. Terkadang ketika kereta mengalami keterlambatan di salah satu stasiun tetapi masih bisa tiba di tujuan akhir tepat waktu itu disebabkan masinis mengoperasikan kereta dengan kecepatan yang melampaui kecepatan rencana untuk mengurangi waktu tempuh perjalanan.

Keterlambatan juga dapat ditimbulkan oleh gangguan. Ciri-ciri gangguan yaitu terjadi kerusakan, kesalahan, atau terjadinya penyimpangan yang mampu mempengaruhi pengoperasian lintas perkeretaapian. Keterlambatan bisa dibagi dalam dua hal yaitu keterlambatan utama dan keterlambatan sekunder.

\section{Teori gap}

Analisis Gap (Analisis Kesenjangan) biasanya digunakan untuk bisnis. Analisis gap dapat menentukan langkah yang perlu diambil agar dapat berpindah dari kondisi yang sekarang menuju kondisi yang diinginkan di masa depan. Secara sederhana Analisis Gap hanya dianggap sebagai analisa kebutuhan semata yaitu untuk menilai kebutuhan saja. Analisis Gap dapat juga diartikan sebagai perbandingan kinerja aktual dengan kinerja potensial atau yang diharapkan. Sebagai sebuah metoda, Analisis Gap digunakan sebagai alat evaluasi bisnis yang menitikberatkan pada kesenjangan kinerja perusahaan saat ini dengan kinerja yang sudah ditargetkan sebelumnya. Semakin kecil perbedaan (disebut juga gap) yang dihasilkan, maka bobot nilainya semakin besar yang berarti memiliki peluang lebih besar untuk mendapatkan keinginan atau tujuan dari penggunaan teori gap ini. (Desy Ika Puspitasari dan Al Fath Riza Kholdani)

\section{METODE PENELITIAN}

\section{Jenis penelitian}

Jenis penelitian yang dilakukan adalah penelitian deskriptif kuantitatif guna untuk menggambarkan karateristik individu, karateristik perjalanan, dan persepsi keterlambatan menurut penumpang yang menggunakan jasa transportasi KRL Green Line.

\section{Lokasi penelitian}

Penelitian dilaksanakan pada Stasiun Tanah Abang dengan alasan:

1. Stasiun Tanah Abang adalah salah satu stasiun kelas 1/besar dan transit pada lintas KRL Greeen Line. Sehingga peran Stasiun Tanah Abang sangat penting dalam keseluruhan operasi KRL Green Line

2. Lokasi Stasiun Tanah Abang yang berdekatan langsung dengan Tanah Abang sebagai pusat perbelanjaan baju terbesar di Jakarta, penting sebagai peran ekonomi di Jakarta.

\section{Responden atau objek studi}

Responden atau objek studi pada penelitian ini adalah penumpang KRL Green Line di Stasiun Tanah Abang. Pertanyaan berbasis kuesioner online Google Forms yang umum digunakan untuk penelitian daring. 


\section{Metode pengumpulan data}

Data pada penelitian ini terdapat dua hal yaitu:

1. Data Primer yang merupakan data kuesioner online untuk menggambarkan persepsi keterlambatan, dan data realiasi keterlambatan keberangkatan Stasiun Tanah Abang

2. Data Sekunder yang merupakan Grafik Perjalanan Kereta Api yang didapat melalui PT. KCI.

\section{Metode analisis data}

Dari hasil kuesioner kepada pengguna KRL, didapat batas toleransi keterlambatan dari wajar hingga parah menurut pengguna KRL Green Line, dan dari data tersebut dibandingkan. Penulis menggunakan Teori gap untuk menyelesaikan analisis ini dengan cara mengklasifikasikan tingkat keterlambatan, dari hasil tersebut bisa didapat hubungan gap antara GAPEKA dan Realisasi. Gap yang dimaksud adalah kesenjangan antara kategori terlambat wajar hingga terlambat parah. Lalu dari tiap kategori wajar hingga parah dianalisis lagi kesenjangan atara terlambat menurut pengguna dan terlambat menurut peraturan menteri. Hasil yang didapat akan lebih bisa merepresentasikan hasil publik terhadap ketepatan kedatangan KRL di Stasiun Tanah Abang.

\section{HASIL DAN PEMBAHASAN}

\section{Data responden}

Data responden didapat melalui penyebaran kuesioner online dengan menggunakan Google Forms. Penyebaran kuesioner ini ditujukan kepada masyarakat yang sering menggunakan jasa transportasi KRL Green Line. Didapatkan hasil responden sebanyak 130 data yang pernah menggunakan jasa transportasi KRL Green Line dan sebanyak 82 orang yang berangkat dari dan bertujuan ke Stasiun Tanah Abang.

\section{Persepsi keterlambatan keberangkatan responden}

1. Persepsi Responden Green Line \& Tanah Abang (kereta lebih cepat dari jadwal). Persepsi responden dapat dilihat di gambar 1 dan 2.

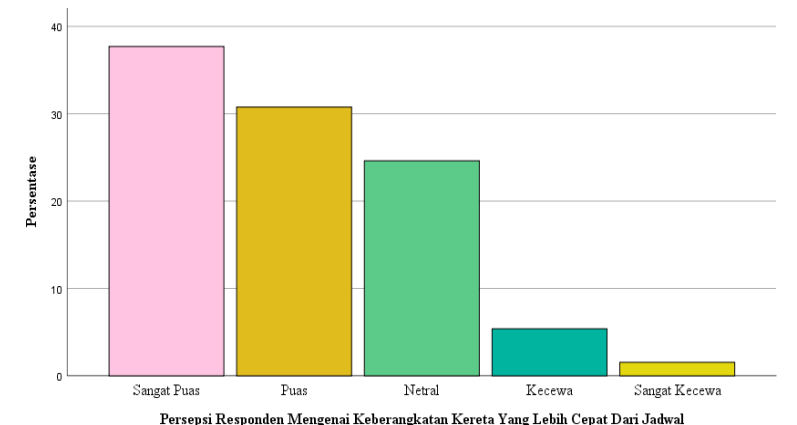

Gambar 1. Persepsi responden Green Line (kereta lebih cepat dari jadwal)

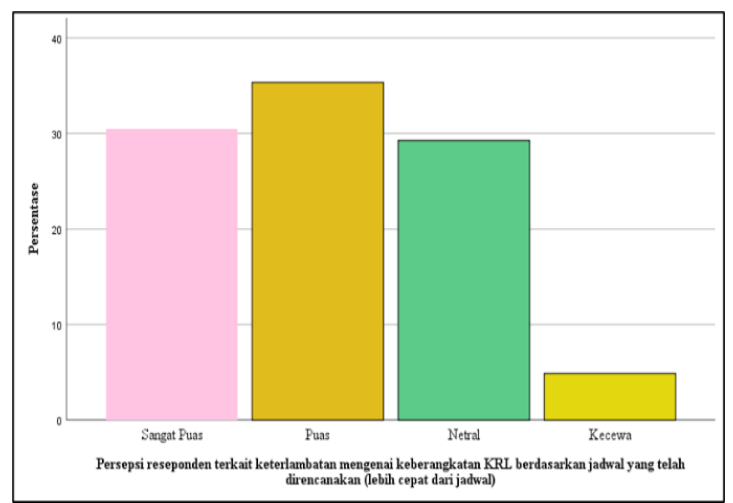

Gambar 2. Persepsi responden stasiun Tanah Abang (kereta lebih cepat dari jadwal) 
2. Persepsi Responden Green Line \& Tanah Abang (Kereta tepat jadwal). Persepsi responden dapat dilihat di gambar 3 dan 4.

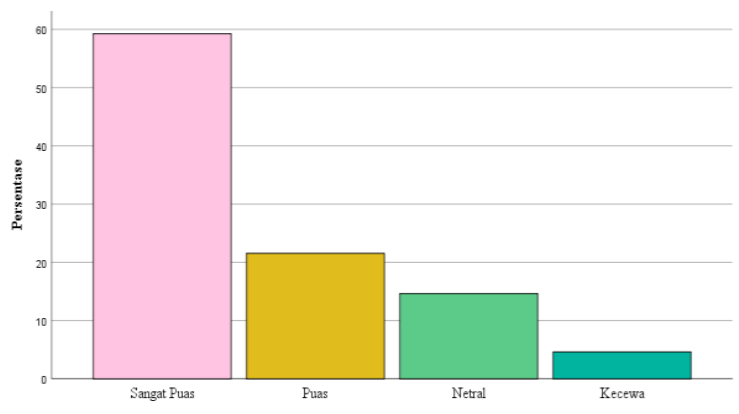

Gambar 3. Persepsi responden Green Line (kereta tepat jadwal)

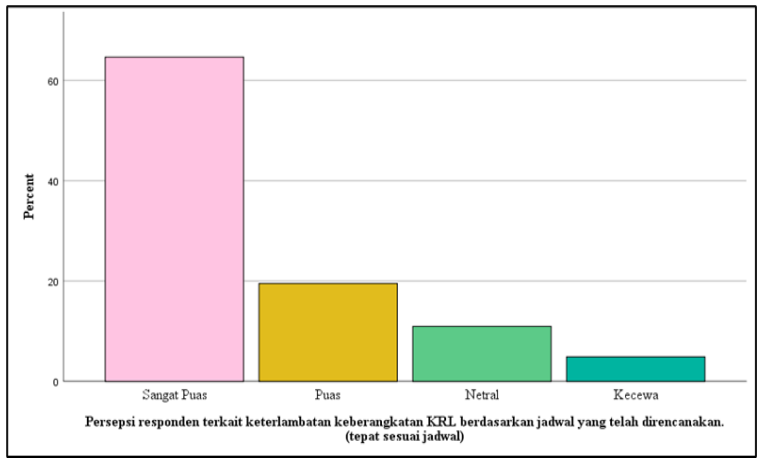

Gambar 4. Persepsi responden Stasiun Tanah Abang (kereta tepat jadwal)

3. Persepsi Responden Green Line \& Tanah Abang (Kereta terlambat $\leq 3$ menit). Persepsi responden dapat dilihat di gambar 5 dan 6

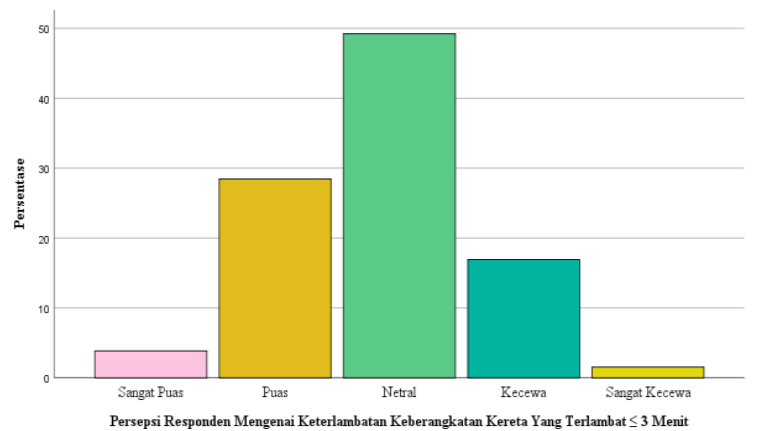

Gambar 5. Persepsi responden Green Line (kereta terlambat $\leq 3$ menit)

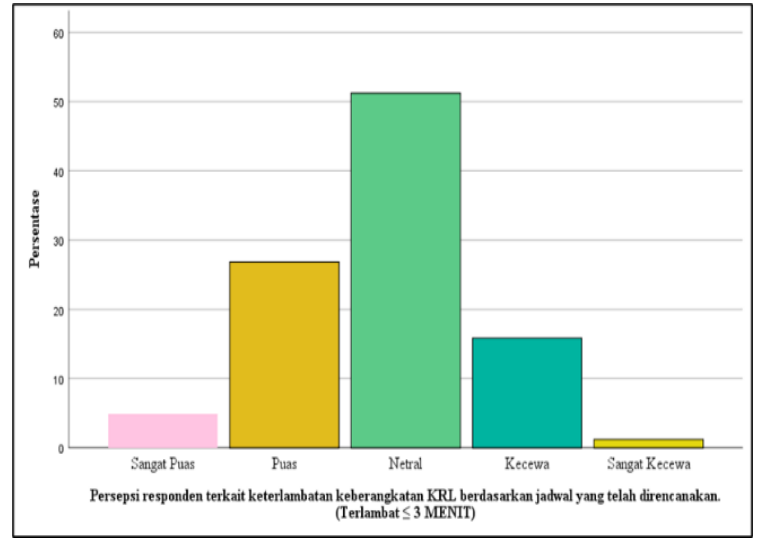

Gambar 6. Persepsi responden Stasiun Tanah Abang (kereta terlambat $\leq 3$ menit)

4. Persepsi Responden Green Line \& Tanah Abang (Kereta terlambat 3-5 menit). Persepsi responden dapat dilihat di gambar 7 dan 8

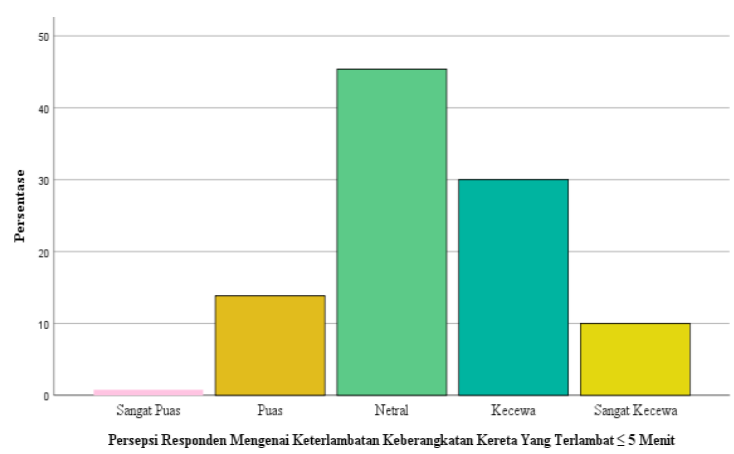

Gambar 7. Persepsi responden Green Line (kereta terlambat 3-5 menit)

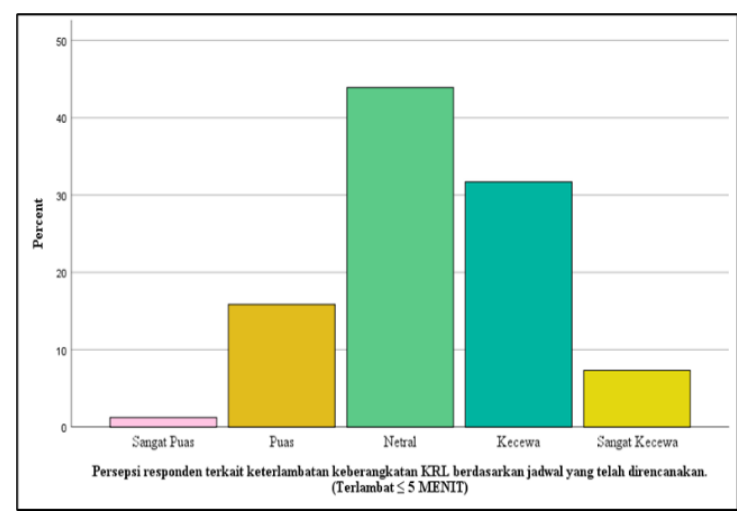

Gambar 8. Persepsi responden Stasiun Tanah Abang (kereta terlambat 3-5 menit) 
5. Persepsi Responden Green Line \& Tanah Abang(Kereta terlambat 5-10 menit). Persepsi responden dapat dilihat di gambar 9 dan 10

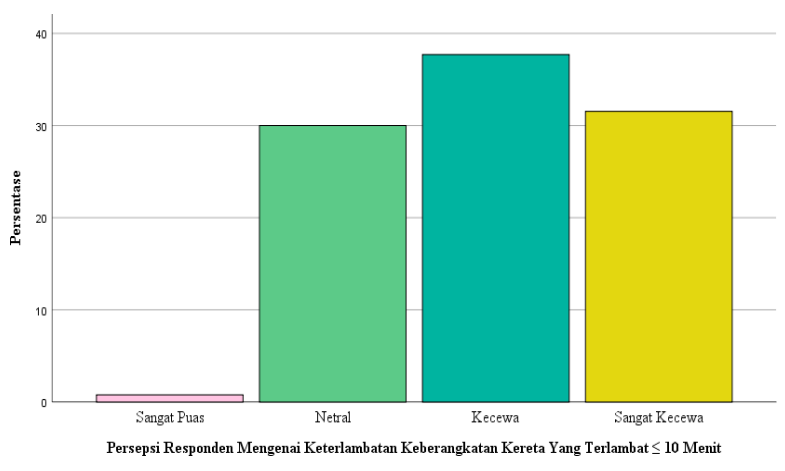

Gambar 9. Persepsi responden Green Line (kereta terlambat 5-10 menit)

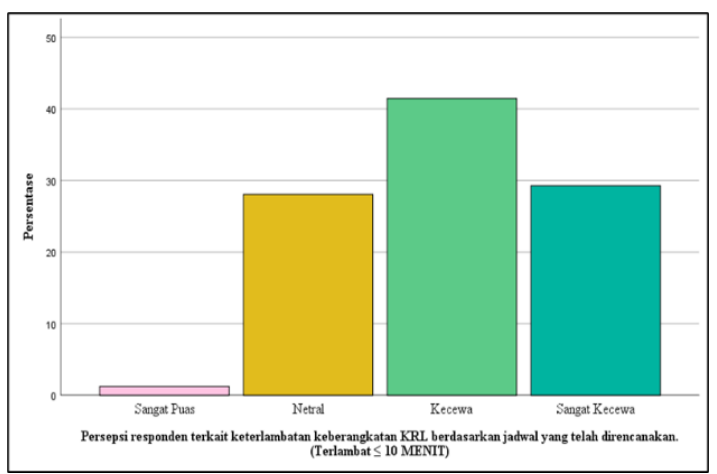

Gambar 10. Persepsi responden Stasiun Tanah Abang (kereta terlambat 5-10 menit)

6. Persepsi Responden Green Line \& Tanah Abang(Kereta terlambat 10-15 menit). Persepsi responden dapat dilihat di gambar 11 dan 12

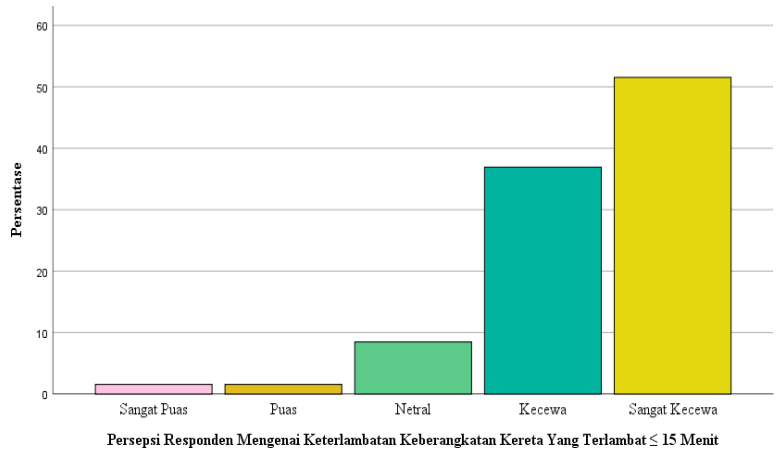

Gambar 11. Persepsi responden Green Line (kereta terlambat $10-15$ menit)

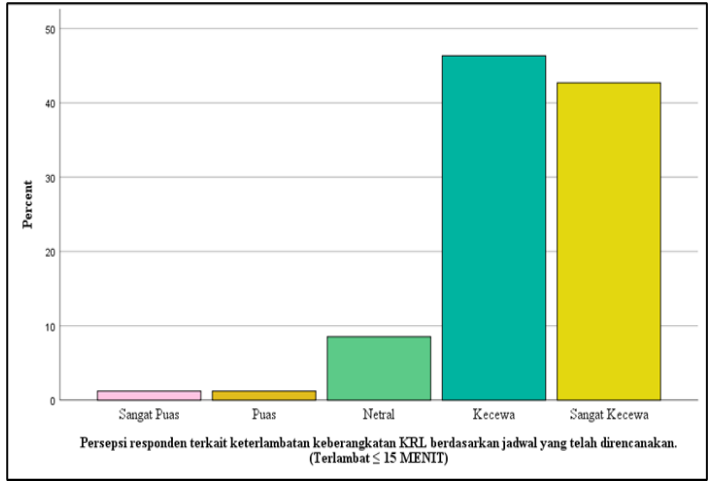

Gambar 12. Persepsi responden Stasiun Tanah Abang (kereta terlambat 10-15 menit)

7. Persepsi Responden Green Line \& Tanah Abang(Kereta terlambat $\geq 15$ menit). Persepsi responden dapat dilihat di gambar 13 dan 14

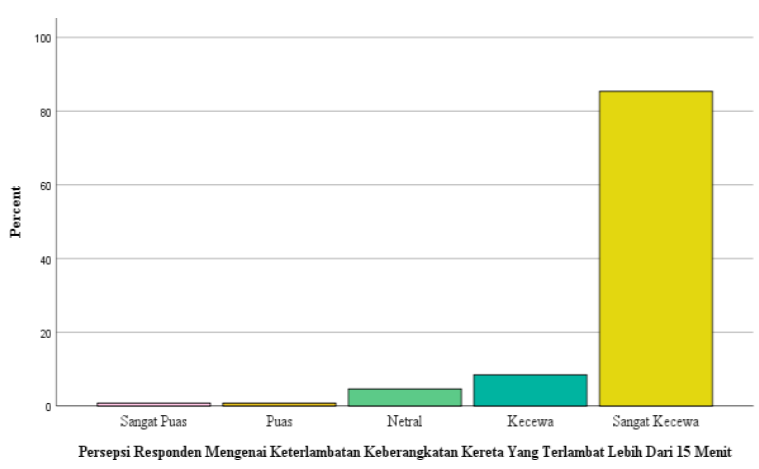

Gambar 13. Persepsi responden Green Line (kereta terlambat $\geq 15$ menit)

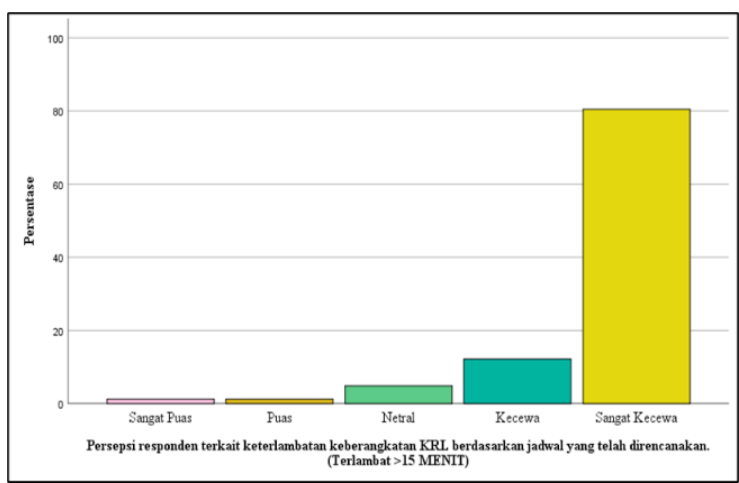

Gambar 14. Persepsi responden Stasiun Tanah Abang (kereta terlambat $\geq 15$ menit) 
8. Pendapat Responden Tanah Abang Ketika Kereta Terlambat Apakah Selalu Diberikan Informasi Oleh Petugas. Pendapat responden dapat dilihat di gambar 15 dan 16

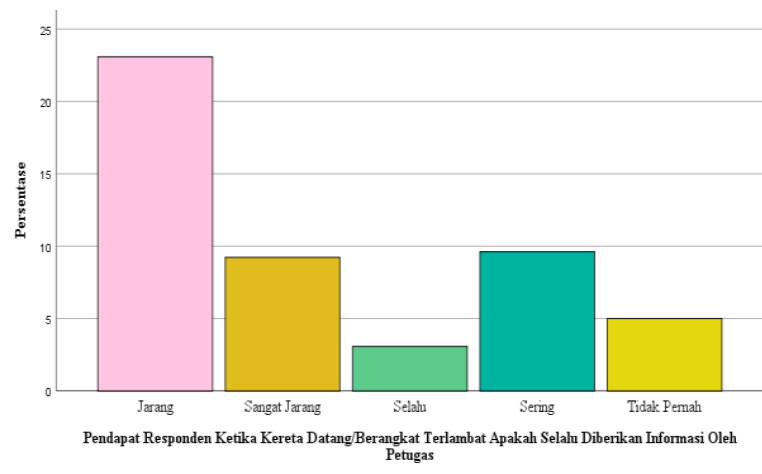

Gambar 15. Pendapat responden Green Line ketika kereta terlambat apakah selalu diberikan informasi oleh petugas

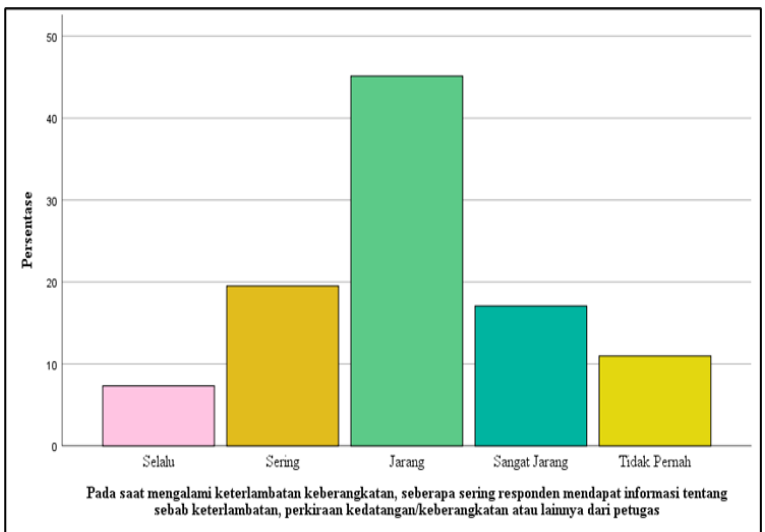

Gambar 16. Pendapat responden Stasiun Tanah Abang ketika kereta terlambat apakah selalu diberikan informasi oleh petugas

\section{Hasil analisis data persepsi keterlambatan responden Green Line}

Untuk melanjutkan penelitian, dibutuhkan data toleransi keterlambatan menurut penumpang seluruh jalur Green Line pada tabel 1, beserta persentase nya di tabel 2, dan dibuat grafik pada gambar 17 untuk menunjukan persilangan toleransi keterlambatan

Tabel 1. Toleransi keterlambatan oleh penumpang di jalur Green Line

\begin{tabular}{cccccc}
\hline \multirow{2}{*}{$\begin{array}{c}\text { Waktu } \\
\text { Keterlambatan }\end{array}$} & \multicolumn{3}{c}{ Menerima } & \multicolumn{2}{c}{ Tidak Menerima } \\
\cline { 2 - 5 } & Sangat Puas & Puas & Netral & Kecewa & $\begin{array}{c}\text { Sangat } \\
\text { Kecewa }\end{array}$ \\
\hline$\leq 3$ menit & 5 & 37 & 64 & 22 & 2 \\
3-5 menit & 1 & 18 & 59 & 39 & 13 \\
5-10 menit & 1 & 0 & 39 & 49 & 41 \\
10-15 menit & 2 & 2 & 11 & 48 & 67 \\
$\geq 15$ menit & 1 & 1 & 6 & 11 & 111 \\
\hline
\end{tabular}

Tabel 2. Persentase toleransi keterlambatan jalur Green Line

\begin{tabular}{cccc}
\hline Waktu Keterlambatan & Menerima & Tidak Menerima & Total \\
\hline$\leq 3$ menit & $82 \%$ & $18 \%$ & $100 \%$ \\
$3-5$ menit & $60 \%$ & $40 \%$ & $100 \%$ \\
$5-10$ menit & $31 \%$ & $69 \%$ & $100 \%$ \\
$10-15$ menit & $12 \%$ & $88 \%$ & $100 \%$ \\
$\geq 15$ menit & $6 \%$ & $94 \%$ & $100 \%$ \\
\hline
\end{tabular}


Abang)

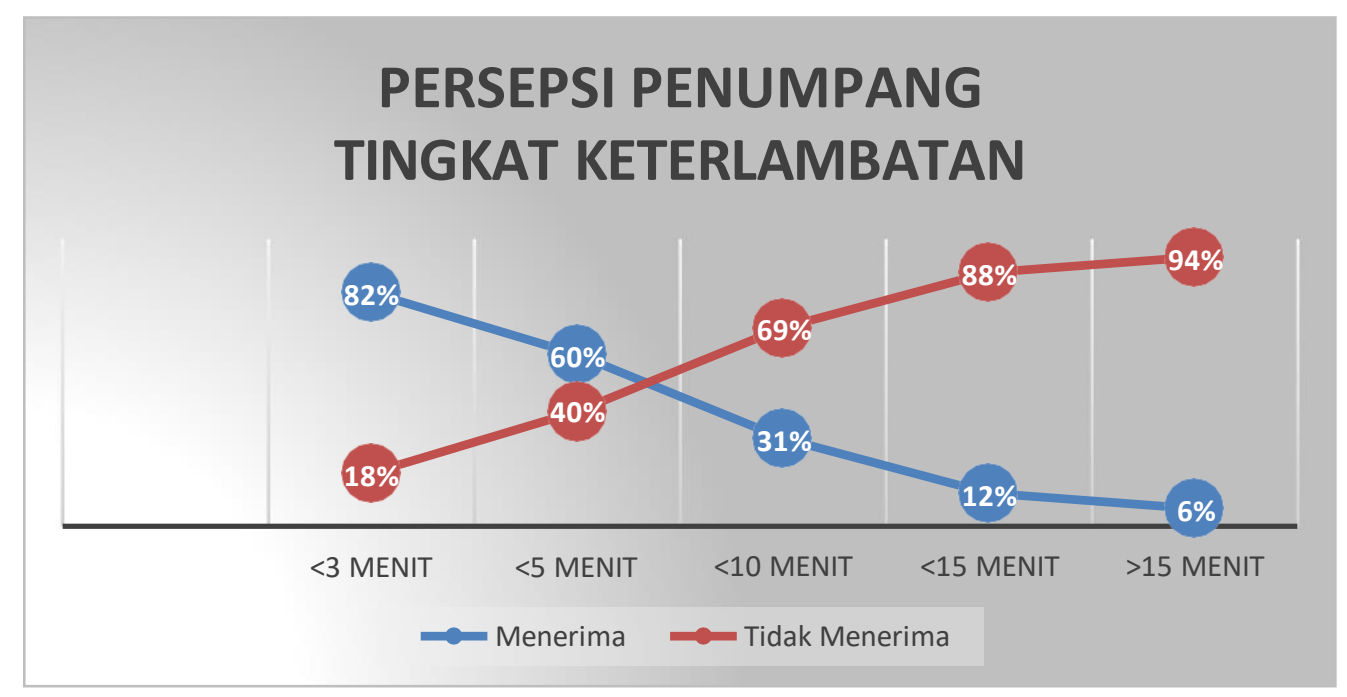

Gambar 17. Toleransi keterlambatan oleh penumpang jalur Green Line

Dari hasil analisis didapatkan bahwa toleransi keterlambatan menurut penumpang jalur Green Line adalah 5 menit.

\section{Hasil analisis data persepsi keterlambatan responden Stasiun Tanah Abang}

Untuk melanjutkan penelitian, dibutuhkan data toleransi keterlambatan menurut penumpang Stasiun Tanah Abang pada tabel 3, beserta persentase nya di tabel 4, dan dibuat grafik pada gambar 18 untuk menunjukan persilangan toleransi keterlambatan

Tabel 3. Toleransi keterlambatan oleh penumpang di Stasiun Tanah Abang

\begin{tabular}{cccccc}
\hline $\begin{array}{c}\text { Waktu } \\
\text { Keterlambatan }\end{array}$ & \multicolumn{3}{c}{ Menerima } & \multicolumn{2}{c}{ Tidak Menerima } \\
\cline { 2 - 3 } & Sangat Puas & Puas & Netral & Kecewa & $\begin{array}{c}\text { Sangat } \\
\text { Kecewa }\end{array}$ \\
\hline$\leq 3$ menit & 4 & 22 & 42 & 13 & 1 \\
$3-5$ menit & 1 & 13 & 36 & 26 & 6 \\
$5-10$ menit & 1 & 0 & 23 & 34 & 24 \\
$10-15$ menit & 1 & 1 & 7 & 38 & 35 \\
$\geq 15$ menit & 1 & 1 & 4 & 10 & 66 \\
\hline
\end{tabular}

Tabel 4. Persentase toleransi keterlambatan di Stasiun Tanah Abang

\begin{tabular}{cccc}
\hline Waktu Keterlambatan & Menerima & Tidak Menerima & Total \\
\hline$\leq 3$ menit & $83 \%$ & $17 \%$ & $100 \%$ \\
$3-5$ menit & $61 \%$ & $39 \%$ & $100 \%$ \\
$5-10$ menit & $29 \%$ & $71 \%$ & $100 \%$ \\
$10-15$ menit & $11 \%$ & $89 \%$ & $100 \%$ \\
$\geq 15$ menit & $7 \%$ & $93 \%$ & $100 \%$ \\
\hline
\end{tabular}




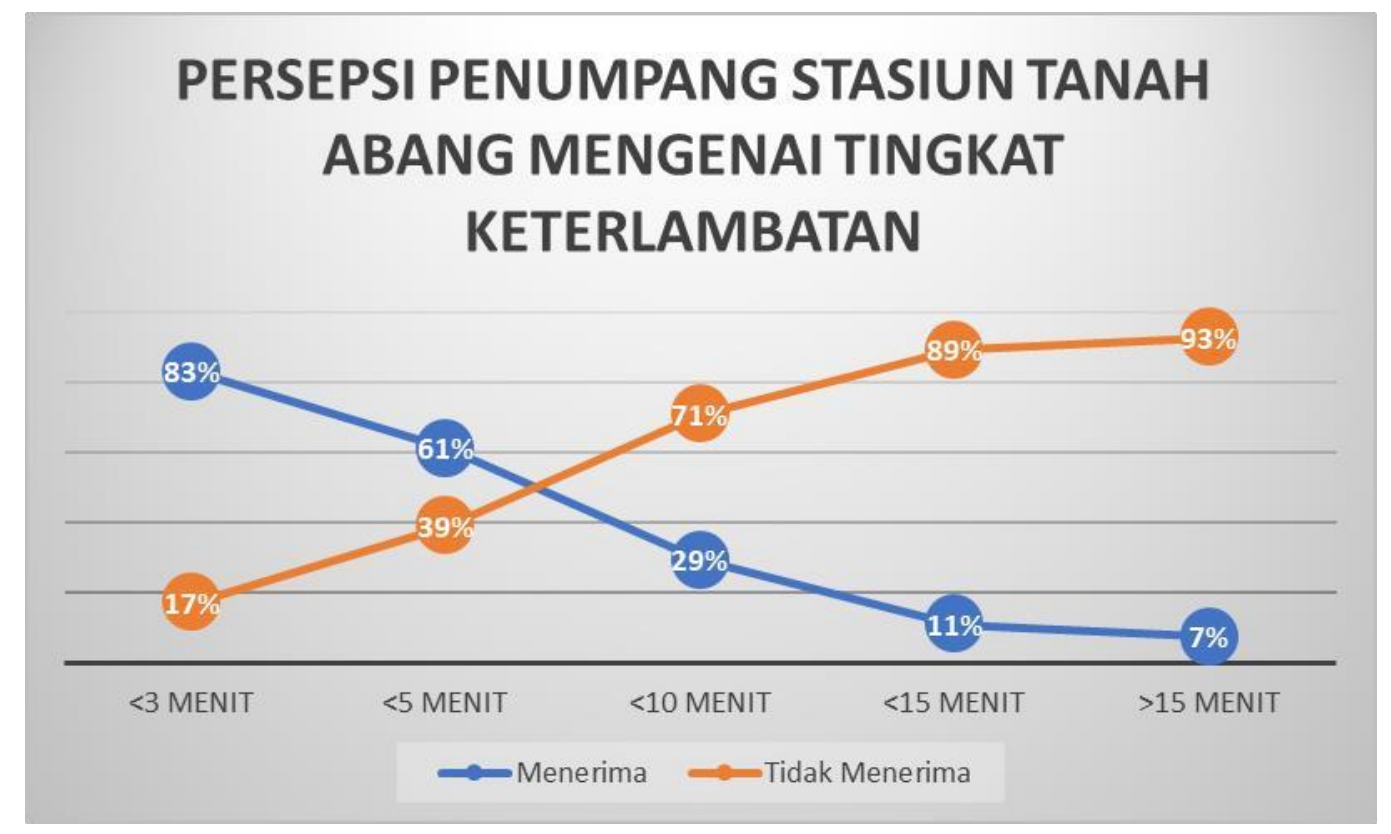

Gambar 18. Toleransi keterlambatan oleh penumpang Stasiun Tanah Abang

Dari hasil analisis didapatkan bahwa toleransi keterlambatan menurut penumpang Stasiun Tanah Abang adalah 5 menit.

\section{Toleransi keterlambatan menurut Peraturan Menteri}

Untuk membandingkan persepsi dengan toleransi keterlambatan, dibutuh perhitungan toleransi keterlambatan menurut Peraturan Menteri nomor 63 tahun 2019. Ditunjukan di tabel 5

Tabel 5. Toleransi keterlambatan menurut Peraturan Menteri

\begin{tabular}{cccc}
\hline $\begin{array}{c}\text { Stasiun } \\
\text { Keberangkatan }\end{array}$ & $\begin{array}{c}\text { Stasiun } \\
\text { Tujuan }\end{array}$ & $\begin{array}{c}\text { Waktu } \\
\text { Tempuh } \\
\text { (menit) }\end{array}$ & $\begin{array}{c}\text { Toleransi } \\
\text { Keterlambatan } \\
\text { (menit) }\end{array}$ \\
\hline Palmerah & Tanah Abang & 6 & 2 \\
Kebayoran & Tanah Abang & 13 & 3 \\
Pondokranji & Tanah Abang & 21 & 5 \\
Jurangmangu & Tanah Abang & 24 & 5 \\
Sudimara & Tanah Abang & 28 & 6 \\
Rawa Buntu & Tanah Abang & 34 & 7 \\
Serpong & Tanah Abang & 37 & 8 \\
Cisauk & Tanah Abang & 42 & 9 \\
Cicayur & Tanah Abang & 45 & 9 \\
Parungpanjang & Tanah Abang & 52 & 11 \\
Cilejit & Tanah Abang & 63 & 13 \\
Daru & Tanah Abang & 68 & 14 \\
Tenjo & Tanah Abang & 73 & 15 \\
Tigaraksa & Tanah Abang & 78 & 16 \\
\hline
\end{tabular}


Tanah Abang - Rangkasbitung (Studi Kasus: Stasiun Tanah

Abang)

Tabel 5. Toleransi keterlambatan menurut Peraturan Menteri (lanjutan)

\begin{tabular}{cccc}
\hline $\begin{array}{c}\text { Stasiun } \\
\text { Keberangkatan }\end{array}$ & $\begin{array}{c}\text { Stasiun } \\
\text { Tujuan }\end{array}$ & $\begin{array}{c}\text { Waktu } \\
\text { Tempuh } \\
\text { (menit) }\end{array}$ & $\begin{array}{c}\text { Toleransi } \\
\text { Keterlambatan } \\
\text { (menit) }\end{array}$ \\
\hline Cikoya & Tanah Abang & 82 & 17 \\
Maja & Tanah Abang & 85 & 17 \\
Citeras & Tanah Abang & 98 & 20 \\
Rangkasbitung & Tanah Abang & 112 & 23 \\
\cline { 3 - 4 } & & Rata-Rata & 11 \\
\hline
\end{tabular}

Setelah dilakukan perhitungan toleransi keterlambatan menurut Peraturan Menteri nomor 63 tahun 2019, maka didapat rata-rata waktu toleransi keterlambatan adalah 11 menit.

\section{Penilaian realisasi waktu keberangkatan terhadap waktu program keberangkatan}

Dalam menghitung data keterlambatan di Stasiun Tanah Abang, diperhitungan di tabel 6 dan tabel 7 untuk jam sibuk pagi.

Tabel 6. Realisasi waktu keberangkatan Stasiun Tanah Abang (menuju Tanah Abang) pagi: 06:00-08:00

\begin{tabular}{ccccc}
\hline $\begin{array}{c}\text { Kode } \\
\text { Kereta }\end{array}$ & Asal Kereta & $\begin{array}{c}\text { Program } \\
\text { Keberangkatan }\end{array}$ & $\begin{array}{c}\text { Realisasi } \\
\text { Keberangkatan }\end{array}$ & $\begin{array}{c}\text { Keterlambatan } \\
\text { (Menit) }\end{array}$ \\
\hline 1927 & Serpong & $6: 02$ & $6: 03$ & $0: 01$ \\
1929 & Maja & $6: 12$ & $6: 13$ & $0: 01$ \\
1931 & Serpong & $6: 22$ & $6: 23$ & $0: 01$ \\
1933 & Parung Panjang & $6: 32$ & $6: 33$ & $0: 01$ \\
1935 & Serpong & $6: 42$ & $6: 43$ & $0: 01$ \\
1937 & Rangkas Bitung & $6: 52$ & $6: 53$ & $0: 01$ \\
1939 & Sudimara & $7: 02$ & $7: 03$ & $0: 01$ \\
1941 & Maja & $7: 12$ & $7: 13$ & $0: 01$ \\
1943 & Rangkas Bitung & $7: 22$ & $7: 23$ & $0: 01$ \\
1945 & Parung Panjang & $7: 32$ & $7: 33$ & $0: 01$ \\
1947 & Serpong & $7: 42$ & $7: 43$ & $0: 01$ \\
1949 & Rangkas Bitung & $7: 52$ & $7: 53$ & $0: 01$ \\
\hline
\end{tabular}

Rata-rata waktu keterlambatan Stasiun Tanah Abang (menuju Tanah Abang) pagi: 06:00-08:00 adalah 1 menit 
Tabel 7. Realisasi waktu keberangkatan Stasiun Tanah Abang (dari Tanah Abang) pagi: 06:00-08:00

\begin{tabular}{ccccc}
\hline $\begin{array}{c}\text { Kode } \\
\text { Kereta }\end{array}$ & $\begin{array}{c}\text { Tujuan Akhir } \\
\text { Kereta }\end{array}$ & $\begin{array}{c}\text { Program } \\
\text { Keberangkatan }\end{array}$ & $\begin{array}{c}\text { Realisasi } \\
\text { Keberangkatan }\end{array}$ & $\begin{array}{c}\text { Keterlambatan } \\
\text { (Menit) }\end{array}$ \\
\hline 1924 & Serpong & $6: 05$ & $6: 08$ & $0: 03$ \\
1928 & Parung Panjang & $6: 15$ & $6: 19$ & $0: 04$ \\
1930 & Rangkas Bitung & $6: 25$ & $6: 27$ & $0: 02$ \\
1932 & Maja & $6: 35$ & $6: 39$ & $0: 04$ \\
1934 & Parung Panjang & $6: 45$ & $6: 46$ & $0: 01$ \\
1936 & Rangkas Bitung & $6: 55$ & $7: 05$ & $0: 10$ \\
1938 & Serpong & $7: 05$ & $7: 06$ & $0: 01$ \\
1940 & Parung Panjang & $7: 15$ & $7: 18$ & $0: 03$ \\
1942 & Rangkas Bitung & $7: 25$ & $7: 28$ & $0: 03$ \\
1944 & Parung Panjang & $7: 35$ & $7: 37$ & $0: 02$ \\
1946 & Maja & $7: 45$ & $7: 47$ & $0: 02$ \\
1948 & Parung Panjang & $7: 55$ & $7: 57$ & $0: 02$ \\
\hline
\end{tabular}

Rata-rata waktu keterlambatan Stasiun Tanah Abang (dari Tanah Abang) pagi: 06:00-08:00 adalah 3 menit Dalam menghitung data keterlambatan di Stasiun Tanah Abang, diperhitungan di tabel 8 dan tabel 9 untuk jam sibuk siang.

Tabel 8. Realisasi waktu keberangkatan Stasiun Tanah Abang (menuju Tanah Abang) siang: 11:00-13:00

\begin{tabular}{ccccc}
\hline $\begin{array}{c}\text { Kode } \\
\text { Kereta }\end{array}$ & Asal Kereta & $\begin{array}{c}\text { Program } \\
\text { Keberangkatan }\end{array}$ & $\begin{array}{c}\text { Realisasi } \\
\text { Keberangkatan }\end{array}$ & $\begin{array}{c}\text { Keterlambatan } \\
\text { (Menit) }\end{array}$ \\
\hline 1987 & Parungpanjang & $11: 02$ & $11: 03$ & $0: 01$ \\
1989 & Maja & $11: 12$ & $11: 13$ & $0: 01$ \\
1991 & Rangkasbitung & $11: 22$ & $11: 23$ & $0: 01$ \\
1993 & Rangkasbitung & $11: 32$ & $11: 33$ & $0: 01$ \\
1997 & Rangkasbitung & $11: 52$ & $11: 53$ & $0: 01$ \\
2001 & Maja & $12: 12$ & $12: 13$ & $0: 01$ \\
2003 & Rangkasbitung & $12: 22$ & $12: 23$ & $0: 01$ \\
2005 & Serpong & $12: 52$ & $12: 53$ & $0: 01$ \\
\hline
\end{tabular}

Rata-rata waktu keterlambatan Stasiun Tanah Abang (menuju Tanah Abang) siang: 11:00-13:00 adalah 1 menit. 
Tabel 9. Realisasi waktu keberangkatan Stasiun Tanah Abang (dari Tanah Abang) siang: 11:00-13:00

\begin{tabular}{ccccc}
\hline $\begin{array}{c}\text { Kode } \\
\text { Kereta }\end{array}$ & $\begin{array}{c}\text { Tujuan Akhir } \\
\text { Kereta }\end{array}$ & $\begin{array}{c}\text { Program } \\
\text { Keberangkatan }\end{array}$ & $\begin{array}{c}\text { Realisasi } \\
\text { Keberangkatan }\end{array}$ & $\begin{array}{c}\text { Keterlambatan } \\
\text { (Menit) }\end{array}$ \\
\hline 1986 & Serpong & $11: 05$ & $11: 05$ & $0: 00$ \\
1988 & Rangkasbitung & $11: 15$ & $11: 15$ & $0: 00$ \\
1990 & Parungpanjang & $11: 25$ & $11: 25$ & $0: 00$ \\
1992 & Parungpanjang & $11: 35$ & $11: 35$ & $0: 00$ \\
1994 & Rangkasbitung & $11: 45$ & $11: 45$ & $0: 00$ \\
1998 & Parungpanjang & $12: 05$ & $12: 05$ & $0: 00$ \\
2002 & Parungpanjang & $12: 15$ & $12: 27$ & $0: 12$ \\
2000 & Rangkasbitung & $12: 30$ & $12: 30$ & $0: 00$ \\
2004 & Rangkasbitung & $12: 45$ & $12: 46$ & $0: 01$ \\
\hline
\end{tabular}

Rata-rata waktu keterlambatan Stasiun Tanah Abang (dari Tanah Abang) siang: 11:00-13:00 adalah 1 menit

Dalam menghitung data keterlambatan di Stasiun Tanah Abang, diperhitungan di tabel 10 dan tabel 11 untuk jam sibuk sore.

Tabel 10. Realisasi waktu keberangkatan Stasiun Tanah Abang (menuju Tanah Abang) sore: 16:00-18:00

\begin{tabular}{ccccc}
\hline $\begin{array}{c}\text { Kode } \\
\text { Kereta }\end{array}$ & Asal Kereta & $\begin{array}{c}\text { Program } \\
\text { Keberangkatan }\end{array}$ & $\begin{array}{c}\text { Realisasi } \\
\text { Keberangkatan }\end{array}$ & $\begin{array}{c}\text { Keterlambatan } \\
\text { (Menit) }\end{array}$ \\
\hline 2041 & Parungpanjang & $16: 02$ & $16: 03$ & $0: 01$ \\
2045 & Rangkasbitung & $16: 22$ & $16: 23$ & $0: 01$ \\
2049 & Serpong & $16: 42$ & $16: 43$ & $0: 01$ \\
2051 & Rangkasbitung & $16: 52$ & $16: 53$ & $0: 01$ \\
2053 & Parungpanjang & $17: 02$ & $17: 03$ & $0: 01$ \\
2055 & Maja & $17: 12$ & $17: 13$ & $0: 01$ \\
2057 & Rangkasbitung & $17: 22$ & $17: 23$ & $0: 01$ \\
2059 & Parungpanjang & $17: 32$ & $17: 33$ & $0: 01$ \\
2061 & Serpong & $17: 42$ & $17: 43$ & $0: 01$ \\
2063 & Rangkasbitung & $17: 52$ & $17: 53$ & $0: 01$ \\
\hline
\end{tabular}

Rata-rata waktu keterlambatan Stasiun Tanah Abang (menuju Tanah Abang) sore: 16:00-18:00 adalah 1 menit. 
Tabel 11 menunjukan realisasi waktu keberangkatan Stasiun Tanah Abang sore.

Tabel 11. Realisasi waktu keberangkatan Stasiun Tanah Abang (dari Tanah Abang) sore: 16:00-18:00

\begin{tabular}{ccccc}
\hline $\begin{array}{c}\text { Kode } \\
\text { Kereta }\end{array}$ & $\begin{array}{c}\text { Tujuan Akhir } \\
\text { Kereta }\end{array}$ & $\begin{array}{c}\text { Program } \\
\text { Keberangkatan }\end{array}$ & $\begin{array}{c}\text { Realisasi } \\
\text { Keberangkatan }\end{array}$ & $\begin{array}{c}\text { Keterlambatan } \\
\text { (Menit) }\end{array}$ \\
\hline 2040 & Serpong & $16: 05$ & $16: 08$ & $0: 03$ \\
2042 & Rangkasbitung & $16: 15$ & $16: 19$ & $0: 04$ \\
2044 & Parungpanjang & $16: 25$ & $16: 28$ & $0: 03$ \\
2046 & Maja & $16: 35$ & $16: 38$ & $0: 03$ \\
2050 & Parungpanjang & $16: 55$ & $16: 58$ & $0: 03$ \\
2052 & Serpong & $17: 05$ & $17: 07$ & $0: 02$ \\
2054 & Parungpanjang & $17: 15$ & $17: 20$ & $0: 05$ \\
2056 & Rangkasbitung & $17: 25$ & $17: 30$ & $0: 05$ \\
2058 & Maja & $17: 35$ & $17: 36$ & $0: 01$ \\
2060 & Parungpanjang & $17: 45$ & $17: 47$ & $0: 02$ \\
2062 & Serpong & $17: 55$ & $17: 58$ & $0: 03$ \\
\hline
\end{tabular}

Rata-rata waktu keterlambatan Stasiun Tanah Abang (dari Tanah Abang) sore: 16:00-18:00 adalah 3 menit.

Hasil analisis rata-rata waktu keterlambatan di Stasiun Tanah Abang:

- Rata-rata waktu keterlambatan Stasiun Tanah Pagi: 06:00-08:00 adalah 1 menit.

- Rata-rata waktu keterlambatan Pagi: 06:00-08:00 adalah 3 menit.

- Rata-rata waktu keterlambatan Siang: 11:00-13:00 adalah 1 menit.

- Rata-rata waktu keterlambatan Stasiun Tanah Abang (dari Tanah Abang) Siang: 11:00-13:00 adalah 1 menit.

- Rata-rata waktu keterlambatan Stasiun Tanah Abang (menuju Tanah Abang) Sore: 16:00-18:00 adalah 1 menit.

- Rata-rata waktu keterlambatan Stasiun Tanah Abang (dari Tanah Abang) Sore: 16:00-18:00 adalah 3 menit.

Setelah mendapatkan nilai waktu keterlambatan yang merupakan nilai realisasi waktu keberangkatan kereta api pada Stasiun Tanah Abang dikurangi dengan nilai program waktu keberangkatan dari GAPEKA, dilakukan penilaian waktu keterlambatan tersebut dengan acuan sebagai berikut:

- Peraturan Menteri Perhubungan Nomor : PM 63 TAHUN 2019 tentang Standar Pelayanan Minimum Untuk Angkutan Orang Dengan Kereta Api

- Hasil dari persepsi pengguna kereta jalur green line mengenai keterlambatan mengenai keterlambatan kereta

- Hasil dari persepsi pengguna kereta di Stasiun Tanah Abang mengenai keterlambatan kereta. 
Tanah Abang - Rangkasbitung (Studi Kasus: Stasiun Tanah

Abang)

\section{KESIMPULAN DAN SARAN}

\section{Kesimpulan}

Dari penelitian diatas dapat disimpulkan kesimpulan sebagai berikut:

- Peraturan Menteri nomor PM 63 tahun 2019 tentang standar pelayanan minimum untuk angkutan orang dengan kereta api menetapkan batas toleransi keterlambatan adalah $20 \%$ dari waktu tempuh yaitu sebesar 11 menit.

- Persepsi keterlambatan menurut pengguna KRL jalur Green Line dan pengguna KRL di Stasiun Tanah Abang adalah sebesar 5 menit.

- Survey kedatangan keberangkatan di Stasiun Tanah Abang dilaksanakan selama 1 hari kerja pada jam sibuk (06.00-08.00), (11.00-13.00), (16.00-18.00), dan seluruh nya masih dibawah batas toleransi keterlambatan menurut Peraturan Menteri nomor 63 tahun 2019 dan toleransi keterlambatan menurut persepsi penumpang

\section{Saran}

Berdasarkan hasil kajian studi dapat diberikan saran sebagai berikut:

- Tingkat keterlambatan kedatangan dan keberangkatan KRL Green Line di Stasiun Tanah Abang berada dibawah batas toleransi menurut Peraturan Menteri PM 63 tahun 2019 dan persepsi pengguna KRL, karenanya perlu dipertahankan dan terus ditingkatkan.

- Penelitian ini dilakukan pada saat Pandemi Coronavirus terjadi di Indonesia, sehingga:

- Responden pengguna KRL menggunakan basis online (google form) yang menurut pandangan penulis belum memberikan gambaran seutuhnya, karena itu diharapkan untuk penelitian selanjutnya agar melakukan survey secara offline baik onboard ataupun offboard untuk mendapatkan hasil yang lebih baik.

- Pelaksanaan survey lapangan terhadap realisasi kedatangan dan keberangkatan KRL Green Line di Stasiun Tanah Abang hanya di lakukan pada 1 hari kerja, karenanya disarankan untuk melakukan survey pada 2 hari kerja dan 1 hari libur untuk mendapatkan hasil yang lebih baik.

\section{DAFTAR PUSTAKA}

Alim dan Ahmad Syahirul. Evaluasi Kinerja Stasiun Kereta Api Malang Kota Baru Berdasarkan SPM K.A. dan IPA (2014).

Apriyadi, Dede. ANALISIS PENGARUH KETEPATAN WAKTU, FASILITAS DAN HARGA TIKET TERHADAP KEPUASAN PENUMPANG KERETA API DI STASIUN PURWOSARI (2017).

Desy Ika Puspitasari, Al Fath Riza Kholdani. PENERAPAN SISTEM PENDUKUNG KEPUTUSAN DENGAN ANALISIS GAP (2017).

Kompas. "Hari Ini dalam Sejarah: Kereta Listrik pertama di Dunia beroperasi." (2019).

Muctar, Edi. PENGARUH KUALITAS PELAYANAN, KETEPATAN WAKTU DAN COSTUMER EXPERIENCE TERHADAP KEPUASAN PENUMPANG KERETA API KALIJAGA JURUSAN SEMARANG-SOLO (2019).

Nyström. Delay Analysis of a Freight Train - an Improvement Case Study From a Steel Company (2005).

Sabri, Yusra dan Ekki Kurniawan. Perancangan Filter Pasif Untuk Mengatasi Harmonisa Pada Gardu Penyearahan Pusat Listrik Aliran Atas - PT KAI Commuter Jabodetabek Indonesia (2012). 